\title{
The asymmetric scent: ringtailed lemurs (Lemur catta) have distinct chemical signatures in left and right brachial glands
}

\section{Leonardo Dapporto}

Accepted: 2 July 2008 / Published online: 22 August 2008

(C) Springer-Verlag 2008

Erratum to: Naturwissenschaften

DOI 10.1007/s00114-008-0407-7

The chemical analyses were funded by the Museo di Storia Naturale e del Territorio, Università di Pisa and performed there by the author. Elisabetta Palagi from the same Institution had a fundamental role in obtaining and collecting the samples.

The online version of the original article can be found at http://dx.doi. org/10.1007/s00114-008-0407-7.

L. Dapporto $(\bowtie)$

Dipartimento di Biologia Evoluzionistica, "Leo Pardi",

Florence University,

via Romana 17,

50125 Firenze, Italy

e-mail: leondap@gmail.com 